\title{
Stabilizing Control for Nonlinear Switched Systems in Two Dimensions with a Geometric Approach
}

Omri F*

Department of Mathematics, University of Sfax, University de Route de l'Aéroport Km 0.5 BP 1169.3029 Sfax, Sfax, Tunisia

\begin{abstract}
The purpose of this paper is to give a sufficient condition for the existence and stability of a hybrid limit cycle for the stabilizing control of a class of switched dynamical systems in $\mathbb{R}^{2}$. This is then illustrated on an Induction Heating Appliance.
\end{abstract}

Keywords: Switched dynamical system; Stability; Hybrid limit cycle; Geometric approach

Mathematics Subject Classification (2010): 93B05, 93C05, 93C10.

\section{Introduction}

Stability theory plays a central role in systems theory and engineering. There are different kinds of stability problems that arise in the study of dynamical systems. In recent years, the problem of stability and stabilization of switched systems has attracted a considerable attention from control community [1-9].

Switched dynamical systems (SDS) are an important class of hybrid systems, which consist of a family of continuous-time or discrete-time subsystems and a switching law that specifies the switching between them [10]. The SDS [2] are found in many fields of application: transport, embedded systems, electronics power, aeronautics, chemical engineering, pharmaceutical, etc. It can be seen in these applications that interactions between discrete events and continuous phenomena give rise to complex system behavior that can only be properly controlled if the hybrid phenomena (continuous and discrete features, and interactions between them) are fully taken into consideration [3,5].

Limit cycles are one of the most important phenomena in nonlinear dynamical systems, and applied in many engineering fields [6]. While stability analysis of limit cycle is a fundamental problem and many theories such as Lyapunov function methods have been proposed, the problem of synthesizing a nonlinear system which has a stable limit cycle is also important $[7,8]$.

In this paper we consider the following time invariant switched dynamic system (SDS) in $\mathbb{R}^{2}$ :

$$
\dot{y}=v_{1} Y^{1}(y)+v_{2} Y^{2}(y)+v_{3} Y^{3}(y)
$$

where $Y_{i}$ is in vector fields of class $C^{1}$, the control $v_{i} \in\{0,1\}$ for $i$ $\in\{1,2,3\}$ verifying the condition $\sum_{i=1}^{3} v_{i}=1$ and the state $\mathrm{y}=\left(\mathrm{y}_{1}, \mathrm{y}_{2}\right)$ is
in $\mathbb{R}^{2}$.

The main objective is to propose a new constructive method for synthesizing a hybrid limit cycle for the SDC (1).

In this paper we use essentially the following result: we consider the nonlinear

$$
\begin{aligned}
& \text { SDS in the plan [7] } \\
& \dot{x}=u_{1} X^{1}(x)+u_{2} X^{2}(x) \text { with } u_{i} \in\{0,1\}, i \in\{1,2\}
\end{aligned}
$$

The solution of the differential equation $\dot{x}=X_{i}(x), i \in\{1,2\}$ after elapsed time $\mathrm{t}$ with initial condition $\mathrm{x}(0)=\mathrm{x}_{0}$ is denoted $X_{t}^{i}\left(x_{0}\right)$.

\section{Definition}

Let us consider $\mathrm{x}_{\mathrm{c} 1}$ and $\mathrm{x}_{\mathrm{c} 2}$ two points in $\mathbb{R}^{2}$, with $\mathrm{x}_{\mathrm{c} 1} \neq \mathrm{x}_{\mathrm{c} 2} \cdot \mathrm{CC}\left(\mathrm{x}_{\mathrm{c} 1}, \mathrm{x}_{\mathrm{c} 2}\right)$ is the hybrid limit cycle of the SDS (2) $\dot{x}=X^{i}(x), i \in\{1,2\}$, between the switching points $\mathrm{x}_{\mathrm{c} 1}$ and $\mathrm{x}_{\mathrm{c} 2}$, if and only if $\left(\delta_{c 1}, \delta_{c 2}\right) \in \mathbb{R}^{2}$ exists such that: $x_{c 1}=X_{\delta_{C 1}}^{1}\left(x_{c 2}\right)$ and $x_{c 1}=X_{\delta_{C 2}}^{2}\left(x_{c 1}\right)$ [7]. Then

$$
\mathrm{CC}\left(\mathrm{x}_{\mathrm{c} 1}, \mathrm{x}_{\mathrm{c} 2}\right)=\left\{\mathrm{X}_{\delta}^{1}\left(\mathrm{x}_{\mathrm{c} 2}\right) / 0 \leq \delta \leq \delta_{\mathrm{c} 1}\right\} \cup\left\{\mathrm{X}_{\delta}^{2}\left(\mathrm{x}_{\mathrm{c} 1}\right) / 0 \leq \delta \leq \delta_{\mathrm{c} 2}\right\} \text {. }
$$

We recall a sufficient condition for existence and stability of a hybrid limit cycle:

Let consider two maps enough smooth $\gamma_{\mathrm{j}}: \mathrm{I} \subset \mathbb{R} \rightarrow \mathbb{R}^{2}, \mathrm{j} \in\{1,2\}$. Suppose that $\gamma_{1}\left(\mathrm{t}_{0}\right)=\gamma_{2}\left(\mathrm{t}_{0}\right)$ (the two trajectories intersect at $\mathrm{t}_{0}$ ) with $\gamma_{1}^{\prime}\left(t_{0}\right) \neq 0$ and $\gamma_{2}^{\prime}\left(t_{0}\right) \neq 0$

\section{Definition}

We call that curves $\gamma_{1}$ and $\gamma_{2}$ are transverse if and only if $\gamma_{1}$ cross the curve $\gamma_{2}$ in $\mathrm{x}_{0=} \gamma_{1}\left(\mathrm{t}_{0}\right)$. We explain this property [7] following Figure 1 .

\section{Notation}

Let us denote as $d^{p i j-1} X^{i}(x)=\frac{d^{P i j} X_{i}^{t}(x)}{\left.d t^{p i j}\right|_{t=0}}$ with $\mathrm{p}_{\mathrm{ij}} \geq 1$ and $\mathrm{i} \neq \mathrm{j}$. We also denote $\mathrm{p}_{\mathrm{ij}}(\mathrm{x})$ is the smallest positive integer such that (with $\gamma_{1}(\mathrm{t})=\mathrm{X}_{\mathrm{t}}^{1}(\mathrm{x})$ and $\left.\gamma_{2}(\mathrm{t})=\mathrm{X}_{\mathrm{t}}^{2}(\mathrm{x})\right)$ :

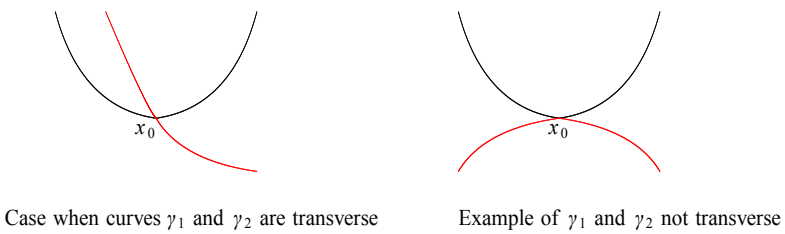

Figure 1: If $\gamma_{1}$ cross the curve $\gamma_{2}$ in $x_{0}=\gamma_{1}\left(t_{0}\right)$.

*Corresponding author: Omri F, Department of Mathematics, University of Sfax University de Route de l'Aéroport Km 0.5 BP 1169 .3029 Sfax, Sfax, Tunisia, Tel: +216 74242 951; E-mail: fawzi_omri@yahoo.fr

Received January 22, 2018; Accepted March 12, 2018; Published March 19 2018

Citation: Omri F (2018) Stabilizing Control for Nonlinear Switched Systems in Two Dimensions with a Geometric Approach. J Appl Computat Math 7: 396. doi: 10.4172/2168-9679.1000396

Copyright: @ 2018 Omri F. This is an open-access article distributed under the terms of the Creative Commons Attribution License, which permits unrestricted use, distribution, and reproduction in any medium, provided the original author and source are credited. 
$\left\langle\mathrm{X}^{\mathrm{j}}(\mathrm{x}) \mid \mathrm{X}^{\mathrm{i}}(\mathrm{x})\right\rangle^{\mathrm{pij}}\left\langle\mathrm{d}^{\mathrm{pij}-1} \mathrm{X}^{\mathrm{i}}(\mathrm{x}) \mid \mathrm{X}^{\mathrm{i}}(\mathrm{x})\right\rangle \models\left\langle\mathrm{X}^{\mathrm{i}}(\mathrm{x}) \mid \mathrm{X}^{\mathrm{i}}(\mathrm{x})\right\rangle^{\mathrm{pij}}\left\langle\mathrm{d}^{\mathrm{pij}-1} \mathrm{X}^{\mathrm{j}}(\mathrm{x}) \mid \mathrm{X}^{\mathrm{i}}(\mathrm{x})\right\rangle$.

\section{Theorem}

The two parameterized curves $\gamma_{1}, \gamma_{2}$ are transverse if $\operatorname{det}\left(\gamma_{1}^{\prime}\left(\mathrm{t}_{o}\right), \gamma_{2}^{\prime}\left(t_{0}\right)\right)=0$ and $\mathrm{p}_{\mathrm{ij}}$ is odd. Otherwise they are not transverse [7].

\section{Definition}

$\forall \mathrm{i} \neq \mathrm{j}$, we define $\mathrm{E}^{\mathrm{ij}}=\left\{\mathrm{z} \in \mathbb{R}^{2} / \operatorname{det}\left(\mathrm{X}^{\mathrm{i}}(\mathrm{x}), \mathrm{X}^{\mathrm{j}}(\mathrm{x})\right)=0,\left\langle\mathrm{X}^{\mathrm{i}}(\mathrm{x}), \mathrm{X}^{\mathrm{j}}(\mathrm{x})\right\rangle<0\right.$ and $\mathrm{p}_{\mathrm{ij}}(\mathrm{z})$ is even $\}$ the set of points with collinear and opposite vector fields $X^{\mathrm{i}}(\mathrm{z})$ and $\mathrm{X}^{\mathrm{j}}(\mathrm{z})$ and these orbits of $\mathrm{z}$ under $\mathrm{X}^{\mathrm{i}}$ and $\mathrm{X}^{\mathrm{j}}$ are not transverse [7].

Let $x_{d}$ the desired operating point of SDS. It is shown in ref. [7], that for $x_{d} \in E^{12}$ there exists an infinity of hybrids limits cycles around the desired point $x_{d}$. This result can be summarized in the following theorem:

\section{Theorem}

Let us consider the SDS (2). For each point $\mathrm{z} \in \mathrm{E}^{12} \neq \phi$ and for any $\mathrm{O}$ open set contain $\mathrm{z}$, there exists a hybrid limit cycle $\mathrm{CC}\left(\mathrm{x}_{\mathrm{c} 1}, \mathrm{x}_{\mathrm{c} 2}\right)$ in $\mathrm{O}$ such that $z \in \overline{\operatorname{Int}\left(\mathrm{CC}\left(\mathrm{x}_{c 1}, \mathrm{x}_{\mathrm{c} 2}\right)\right)}$.

\section{Sufficient Condition of Existence and Stability of a Hybrid Limit Cycle}

Let us consider the time invariant switched dynamic system (SDS) (1)

$$
\dot{y}=v_{1} Y^{1}(y)+v_{2} Y^{2}(y)+v_{3} Y^{3}(y) \text {. }
$$

\section{Notation}

We denote

$\mathrm{E}=\left\{\mathrm{y} \in \mathbb{R}^{2}, \mathrm{Y}^{1}(\mathrm{y})=\alpha_{1} \mathrm{Y}^{2}(\mathrm{y})+\alpha_{2} \mathrm{Y}^{3}(\mathrm{y})\right.$, with $\alpha_{\mathrm{i}}>0$, for $\left.\mathrm{i} \in\{1,2\}\right\}$

the set of all points $y$ such that the vector $\mathrm{Y}^{1}(\mathrm{y})$ is represented as a linear combination of $\left(\mathrm{Y}^{2}(\mathrm{y}), \mathrm{Y}^{3}(\mathrm{y})\right)$ with positive coefficient.

\section{Theorem}

For all $\mathrm{y} \in \mathrm{E}$ and the desired point $\mathrm{x}_{\mathrm{d}}$ of $\mathrm{SDC}(1)$ is in $\mathrm{E}^{23}$, there exists a hybrid limit cycle $\mathrm{CC}\left(\mathrm{x}_{\mathrm{c}}, \mathrm{y}_{\mathrm{c}}\right)$ such that $x_{d} \in \overline{\operatorname{Int}\left(C C\left(x_{c}, y_{c}\right)\right)}$.

\section{Proof}

For all $\mathrm{y} \in \mathrm{E}$, we have

$\mathrm{Y}^{1}(\mathrm{y})=\alpha_{1} \mathrm{Y}^{2}(\mathrm{y})+\alpha_{2} \mathrm{Y}^{3}(\mathrm{y})$, for $\mathrm{y} \in \mathbb{R}^{2}$

Thus, the system (1) becomes

$$
\begin{aligned}
\dot{y} & =\left(\alpha_{1} v_{1}+v_{2}\right) Y^{2}(y)+\left(\alpha_{2} v_{1}+v_{3}\right) Y^{3}(y) \\
& =u_{1} Y^{2}(y)+u_{2} Y^{3}(y)
\end{aligned}
$$

By using the fact that $x_{d} \in E^{23}$ and by using the theorem (2) there exists a hybrid limit cycle around of $\mathrm{x}_{\mathrm{d}}$.

\section{Remark}

In the case where the control $\mathrm{v}_{1}=0$, the SDS (1) rest around of point $x_{d}$. Otherwise, we can reach the point $x_{d}$ by the vector field $Y^{1}(y)$.

\section{Three Control Strategies of an Induction Heating Appliance}

An induction heating appliance (induction hob) is made of adaptable-diameter inductors. Currently, one resonant inverter is dedicated to supplying each winding $[6,10]$. The current variations in the inductor produce heat energy in the metal vessel placed on the winding. The inductor and the load (vessel) are each equivalent to a resistor and an inductor in series. In the system studied here, the global inductor $(\mathrm{R}, \mathrm{L})$ is in series with a capacitor $\mathrm{C}$ to compose the resonant inverter (voltage inverter). The voltage source, E, provides adjustable DC voltage through a thyristors or diodes rectifier. An adequat DC voltage is applied to the series RLC circuit, with the control of the opening and closure of the four switches $T_{1}^{1}, T_{1}^{2}, T_{2}^{1}$ and $T_{2}^{2}$. Three configurations are possible (Figure 2):

$$
\begin{aligned}
& T_{1}^{1} \text { and } T_{1}^{2} \text { closed } \\
& T_{1}^{2} \text { closed and } T_{1}^{2} \text { open } \\
& T_{1}^{1} \text { open and } T_{1}^{2} \text { closed. }
\end{aligned}
$$

The objective is to control the $\mathrm{u}_{\mathrm{C}}$ voltage on a hybrid limit whatever the load.

The standard state-space representation of the induction heating appliance, with power state variables, is the following equation (3):

$$
\left[\begin{array}{l}
\dot{i}_{L} \\
\dot{u}_{C}
\end{array}\right]=\left[\begin{array}{cc}
-R / L & -1 / L \\
1 / C & 0
\end{array}\right]\left[\begin{array}{l}
i_{L} \\
u_{C}
\end{array}\right]+\rho\left[\begin{array}{c}
\frac{2 E}{0} \\
0
\end{array}\right]-\left[\begin{array}{c}
\frac{E}{L} \\
0
\end{array}\right]
$$

with $\rho$ the control signal of the switches. If $\rho=\frac{1}{2}$, the configuration 1 is active, if $\rho=1$, the configuration 2 is active and, if $\rho=0$, the configuration 3 is active. Noting the state $y=\left[i_{L} u_{C}\right]^{T}$. The system (3) is equivalent to (1) with

$$
\begin{aligned}
& Y^{1}(y)=A y, Y^{2}(y)=A y+B \text { and } Y^{3}(\mathrm{y})=\mathrm{Ay}-\mathrm{B} \\
& \text { where } \\
& \mathrm{A}=\left[\begin{array}{cc}
-R / L & -1 / L \\
1 / C & 0
\end{array}\right] \text { and } B=\left[\begin{array}{c}
\frac{E}{L} \\
0
\end{array}\right]
\end{aligned}
$$

The parameter values are as follows: $R=22 \Omega, C=47 \mu \mathrm{F}, \mathrm{L}=0.2 \mathrm{H}$, $\mathrm{E}=20 \mathrm{~V}$.

The set of possible points of equilibrium for this system is

$\left\{\mathrm{y}=\left(\mathrm{y}_{1}, \mathrm{y}_{2}\right) \in \mathbb{R}^{2}\right.$ such that $\mathrm{y}_{1}=0$ and $\left.-\mathrm{E} \leq \mathrm{y}_{2} \leq \mathrm{E}\right\}$

It clear that

$$
\mathrm{Y}^{1}(\mathrm{y})=\mathrm{Y}^{2}(\mathrm{y})+\mathrm{Y}^{3}(\mathrm{y})
$$

Let us now calculate the set $E^{23}=\left\{\mathrm{z} \in \mathrm{R}^{2} / \operatorname{det}\left(\mathrm{Y}^{2}(\mathrm{y}), \mathrm{Y}^{3}(\mathrm{y})\right)=0,\langle\mathrm{Y}\right.$ $\left.{ }^{2}(\mathrm{y}), \mathrm{Y}^{3}(\mathrm{y})\right\rangle<0$ and $\mathrm{p}_{23}(\mathrm{z})$ is even $\}$.

We have.

$$
\left\{\begin{array} { l } 
{ \operatorname { d e t } ( Y ^ { 2 } ( \mathrm { y } ) , \mathrm { Y } ^ { 3 } ( \mathrm { y } ) ) = 0 } \\
{ \langle Y ^ { 2 } ( \mathrm { y } ) , \mathrm { Y } ^ { 3 } ( \mathrm { y } ) \rangle < 0 }
\end{array} \Rightarrow \left\{\begin{array}{l}
y_{1}=0 \\
-E<y_{2}<E
\end{array}\right.\right.
$$

Furthermore, The condition $\mathrm{p}_{23}=2$ such that the trajectories of both $\mathrm{Y}^{2}$ and $\mathrm{Y}^{3}$ are not transverse is checked. Thus,

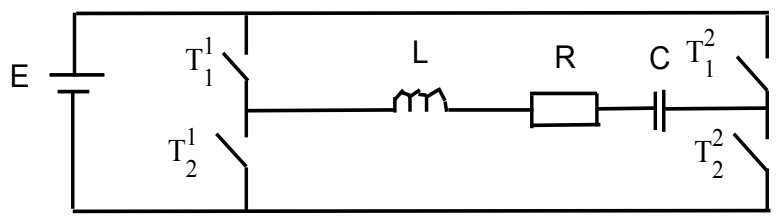

Figure 2: Induction Heating Appliance. 
Citation: Omri F (2018) Stabilizing Control for Nonlinear Switched Systems in Two Dimensions with a Geometric Approach. J Appl Computat Math 7: 396. doi: 10.4172/2168-9679.1000396

Page 3 of 3

$\mathrm{E}^{23}=\left\{\mathrm{z} \in \mathrm{R}^{2} / \mathrm{A}^{-1} \mathrm{~B}<\mathrm{z}<-\mathrm{A}^{-1} \mathrm{~B}\right.$ and $\left.\mathrm{p}_{23=} 2\right\}$ is the straight line that connects the two stable point $x_{e 1}$ et $x_{e 2}$ of vector fields $Y^{2}(y)$ and $Y^{3}(y)$. It follow that for each point in $\mathrm{E}^{23}$ there exists a hybrid limit cycle. If we choose $x_{d}=\left(0, \frac{E}{6}\right)$ then $\mathrm{x}_{\mathrm{d}} \in \mathrm{E}^{23}$.

Figure 3 gives the dynamics of the two modes of the SDS, associated with vector fields $\mathrm{Y}^{2}(\mathrm{y})$ (red curves) and $\mathrm{Y}^{3}(\mathrm{y})$ (blue curves) as well as the set $\mathrm{E}$ (straight line in black).

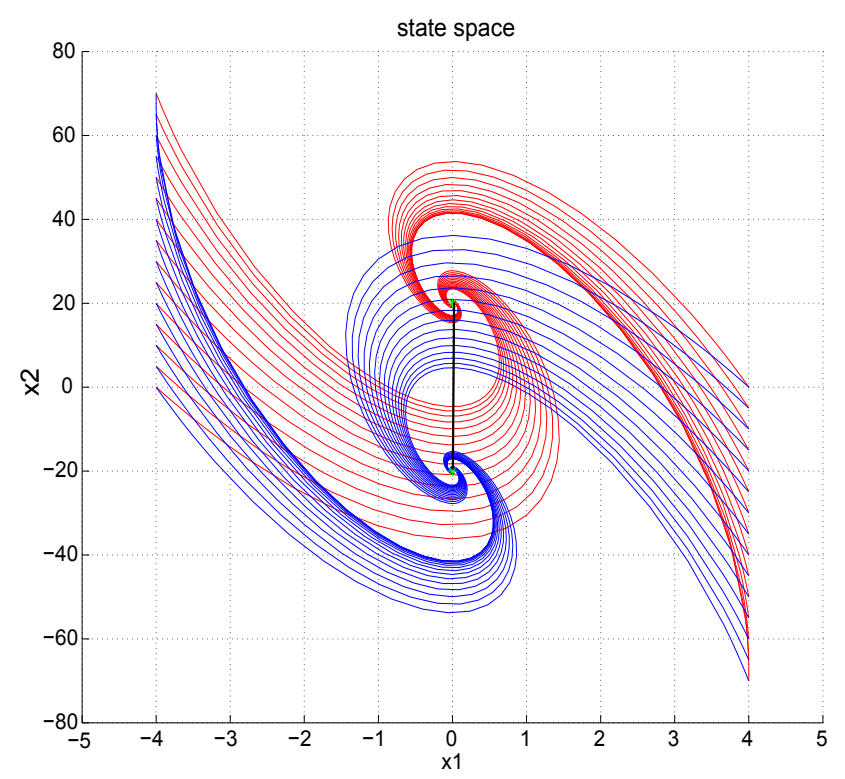

Figure 3: Dynamics of $Y^{2}(y)$ and $Y^{3}(y)$ and the set $E^{23}$.

\section{Conclusion}

The current variations in the inductor produce heat energy in the metal vessel placed on the winding. The inductor and the load (vessel) are each equivalent to a resistor and an inductor in series. With power state variables, $\rho$ the control signal of the switches. If $\rho=\frac{1}{2}$, the configuration 1 is active, if $\rho=1$, the configuration 2 is active and, if $\rho=0$, the configuration 3 is active. It can be seen in these applications that interactions between discrete events and continuous phenomena give rise to complex system behavior that can only be properly controlled if the hybrid phenomena (continuous and discrete features, and interactions between them) are fully taken into consideration.

\section{References}

1. Agrachev AA, Liberzon D (2001) Lie-algebraic stability criteria for switched systems. SICON 40: 253-269.

2. VanderSchaft AJ, Schumacher $H(2000)$ An introduction to hybrid dynamical systems", Springer.

3. Liberzon D, Morse AS (1999) Basic problems in stability and design of switched systems", IEEE Trans Automat Contr 19: 5970.

4. Liberzon D, Hespanha JP, Morse AS (1999) Stability of switched systems: a Lie-algebraic condition. Syst Control Lett 37: 117-122.

5. Liberzon D (2003) Switching in Systems and Control.

6. Paesa D, Franco C, Llorente S, Lopez-Nicolas G, Sagues C (2011)"Adaptive Simmering Control for Domestic Induction Cookers. 47: 2257-2267.

7. Ben S J, Jerbi H, Valentin C, Xu CZ (2011) Geometric synthesis of a hybrid limit cycle for the stabilizing control of a class of nonlinear switched dynamical systems. Syst Control Lett 60: 967976.

8. Ben S J, Valentin C, Jerbi H (2009) Quadratic Common Lyapunov Fonction computation and planar linear switched system stabilization.pp: 23-26 .

9. Zhao J, Dimirovski G (2004) Quadratic stability of a class of switched nonlinear systems. IEEE Trans Automat Contr 49: 574-578.

10. Luca O, Maussion P, Dede E, Burdo JM (2014) Induction Heating Technology and its Applications: Past Developments, Current Technology, and Future Challenges. IEEE Trans Automat Contr 61: 2509 - 2520. 